\title{
The Effect of Growth Hormone Treatment on Adult Height of Children With Idiopathic Short Stature: A Systematic Review and Meta-Analyses
}

\author{
Shoboo Rahmati ${ }^{\mathrm{a}}$, Nasrin Pourattar ${ }^{\mathrm{a}}$, Milad Azami ${ }^{\mathrm{a}}$, Ali Depisheh ${ }^{\mathrm{b}}$, Reza Najafic \\ Kourosh Sayehmirid, e
}

\begin{abstract}
Idiopathic short stature (ISS) is a kind of low height among children in which children's height is more than 2 standard deviation (SD) scores below the mean score of the height of other children with the same age and gender. It is one of the disorders that physicians use growth hormone for its treatment. Therefore, the purpose of the current study was to investigate the effect of growth hormone treatment on the adulthood height of children with ISS through meta-analysis method. In total 20 studies with a sample size of 1,517 were included in the meta-analysis through searching in external databases, including Web of science, Pubmed, Cochran, Medline, Embase, Springer, Scopus, and Science Direct using mesh keywords as growth hormone, final height, adult height, and idiopathic short stature. Mean score and SD were utilized for measuring any increase in height growth and random effect model was used for combining studies. Further, $\mathrm{I}^{2}$ index was used for determining the heterogeneity of studies. Results indicated that before treatment, according to standard mean difference percentile of children's height was -1.64 (95\% confidence interval (CI): -2.01 to -1.28 ) which is equal to $5 \%$. After treatment, according to standard mean difference percentile of children's height came out to be 0.11 (95\% CI: $0.07-0.14)$ which is equal to $54.38 \%$. This indicates that percentile of children's height has increased as a result of treatment with growth hormone. Through combining the results of all studies, the mean score for participants' height before treatment was $5 \%$ and after treatment it reached $54 \%$. Therefore, obtained mean difference for adult height after treatment with growth hormone was reported to be more than 1.4 SD score (about $7.6 \mathrm{~cm}$ ). Growth hormone can be influential in increasing the
\end{abstract}

Manuscript accepted for publication March 24, 2017

aStudent Research Committee, Ilam University of Medical Sciences, Ilam, Iran

bPublic Health Faculty, Ilam University of Medical Sciences, Ilam, Iran

cDepartment of Pediatric Endocrinology and Metabolism, Ilam University of Medical Sciences, Ilam, Iran

dPsychosocial Injuries Research Center, Ilam University of Medical Sciences, Ilam, Iran

${ }^{\mathrm{e} C o r r e s p o n d i n g ~ A u t h o r: ~ K o u r o s h ~ S a y e h m i r i, ~ P s y c h o s o c i a l ~ I n j u r i e s ~ R e s e a r c h ~}$ Center, Ilam University of Medical Sciences, Ilam, Iran. Email: Sayehmiri@ razi.tums.ac.ir

doi: https://doi.org/10.14740/jem411w adult height of children with ISS.

Keywords: Idiopathic short stature; Adult height; Final height; Growth hormon; Meta-analysis

\section{Introduction}

Growth hormone which is secreted from hypophysis due to proteins metabolism would increase their biosynthesis in cells which, in turn, increases the number and the dimensions of cells. Furthermore, growth hormone would stimulate growth plate of long bones before maturity. After maturation, these growth plates will become bony, thus the linear growth of bones stops and their diagonal growth will continue. Any kind of disorder in growth hormone secretion would decrease the growth rate and cause growth disorder in children. As a result, height of these children would be lower than the average height of other children of the same age and gender [1-3]. According to the reports of UNISEF regarding nourishment in 2013, approximately one child of every four children less than 5 years of age suffer from short stature in the world, $3.4 \%$ of which are living in Africa and South Asia. Further, in this report, Iran was among no data countries [4]. Short stature is classified into three main groups: initial growth disorder (regarding growth plate), secondary growth disorder (changes in the growth plate physiology), and the third group for which there is no specified reason, i.e. idiopathic short stature (ISS) [5]. ISS is predicated upon the assumption that the child's height is more than two standard deviation (SD) scores below the average height of children of the same age and gender on the condition that he/ she has no systematic, trophic, or chromosomal disorder [6, 7]. It is estimated that approximately $80 \%$ of children were diagnosed with ISS [8]. Although growth hormone treatment increases the height growth rate, there is disagreement over its use for the treatment of ISS and how much it can increase the height [9-12]. In this regard, many studies have been conducted throughout the world; accordingly, the purpose of this study was to conduct a meta-analysis in order to bring all documents together and arrive at a more accurate conclusion as to the effectiveness of growth hormone treatment among children with ISS. 


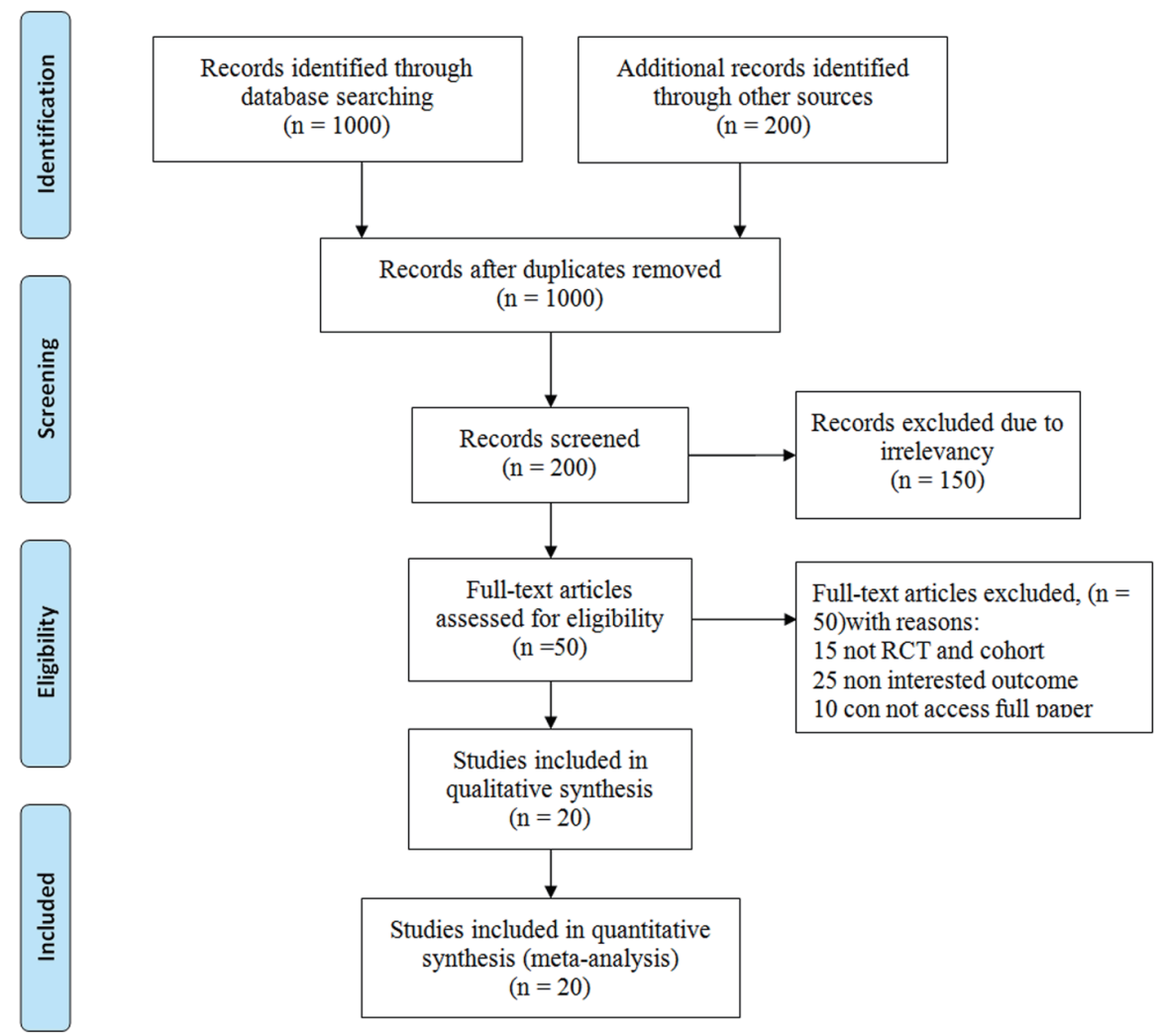

Figure 1. The flowchart stages of entering the articles into meta-analysis

\section{Methodology}

\section{Searching strategy}

The present study was a systematic review and meta-analysis and has been conducted based on PRISMA guideline that reviewed articles and theses investigating the effect of growth hormone treatment on children diagnosed with ISS from 1995 to March 2016 [13]. Articles were collected through using mesh keywords from external databases including Web of science, Pubmed, Cochran, Medline, Embase, Springer, Scopus, and Science Direct. Also, Google scholars search engine was utilized. Moreover, searching was carried out using keywords such as "growth hormone", "final height", "adult height", and "idiopathic short stature" and their Persian equivalents using "and" and "or" conjunctions. In addition, a list of related articles was also utilized for finding articles.

\section{Exclusion and inclusion criteria}

In the current study, main inclusion criteria for the studies were initial short stature, defined as height more than 2 SD scores below the mean; peak growth hormone responses greater than $10 \mu \mathrm{g} / \mathrm{L}$; prepubertal stage; no previous growth hormone therapy; and no comorbid conditions that would impair growth, such as chromosomal abnormalities, bone diseases, chronic diseases interfering with growth, treatment with steroids or sex steroids, and dysmorphic syndromes. Adult height was considered achieved when growth rate was $<1.5 \mathrm{~cm} /$ year or bone age was 15 years in females and 16 years in males [14].

Exclusion criteria included: 1) exclusion of studies not involving children with ISS; 2) non-random sample size; 3) unrelated topics; 4) insufficient data; 5) lack of required information and unavailability of the full text of the studies; and 6) studies with low quality. In order to reduce tropism, searching and data extraction were carried out by two researchers independently.

\section{Study selection}

Study selection was carried out by two reviewers independently. At first, duplicate studies were removed and studies' abstracts were investigated; then, if related, they were included. Finally, the full texts of the remained articles were read and if unrelated they were excluded. Following that, randomized controlled trials and cohort studies in which SD and 95\% CI were reported were included in the meta-analysis.

\section{Data extraction}

In order for decreasing bias and error in data gathering, data extraction was done by two researchers independently using 
data extraction form (author name, publication year, country, continent, number of participants, average treatment start age, SD of treatment start age, mean score of treatment start height, SD of treatment start height, amount of consumed dose, mean score of treatment duration, SD of treatment duration, estimation of final adult height, SD of final adult height and P-value). If articles were available, special questions or ambiguities about the data were asked from the author through email. Each of researchers compared the extracted data and any conflict as to the data was discussed in the presence of a third party as a consultant in order to come to an agreement.

\section{Statistical analysis}

Mean, SD and z-score of height before and after treatment were defined as effects size. Z-score was computed using normal distribution. Standard mean difference (SMD) for each study was computed. To pool effects size (ES) or SMD among studies, random effects models were used. Heterogeneity of studies was checked using $\mathrm{Q}$ and $\mathrm{I}^{2}$ statistics and meta-regression. We considered a mean difference in adult height of more than 0.9 SD scores (about $6 \mathrm{~cm}$ ) as a satisfactory response to growth hormone therapy [13]. Subgroup analysis was done according to the dose of growth hormone and duration of treatment. Publication bias was checked with funnel plot and Egger test. A P-value $<0.05$ was considered as significance level. Data were analyzed using STATA software, Ver. 11.

\section{Results}

The current study was a systematic review conducted from 1995 to March 2016. Twenty studies related to the effect of treatment with growth hormone on the adult height of children with ISS with a total sample size of 1,517 were included in the meta-analysis (Fig. 1 and Table 1 [10, 11, 15-32]).

\section{Mean score of participants' treatment start age}

Generally, there were 20 related studies including four studies of cohort type with an SMD of 11.34 (95\% CI: 10.48 12.20) for treatment start age, six clinical trial studies without a control group with an SMD of 9.73 (95\% CI: $8.84-10.63)$ for treatment start age, seven non-random clinical trial studies with a control group and an SMD of 10.63 (95\% CI: 9.83 11.48) for treatment start age, and three random clinical trial studies with a group and an SMD of 10.07 (95\% CI: 5.90 14.25). After combining studies using random effects model, SMD at treatment start age was 10.42 years (95\% CI: 9.90 - 11.24) (Fig. 2).

\section{Mean score of height before treatment start}

There were four cohort studies with an SMD of -1.24 (95\% CI: -1.69 to -0.79$)$ for treatment start height, six clinical trial studies without a control group with an SMD of $-1.83(95 \%$ CI: -2.70 to -0.97 ), seven non-random clinical trial studies with a control group and an SMD of -1.70 (95\% CI: -2.01 to -1.40) for treatment start height, and three random clinical trial studies without a control group with an SMD of -1.62 (95\% CI: -1.82 to -1.41 ) for treatment start height. When results of studies were combined using random effects model, SMD for treatment start height was -1.64 (95\% CI: -2.01 to -1.28$)$ which is equal to $5 \%$ (their height was higher than $5 \%$ of participants) (Fig. 3).

\section{Mean score of height after treatment}

It has been indicated that the standardized mean score of height in the three cohort studies was 0.11 (95\% CI: 0.08 - 0.14), the standardized mean score of height in the six clinical trial studies without control group was 0.06 (95\% CI: $0.05-0.07)$, standardized mean score of height in the seven non-random clinical trial studies with a control group was 0.19 (95\% CI: $0.07-0.32)$, and the standardized mean score of height in the three random clinical trial studies with a control group was 0.17 (95\% CI: 0.01 - 0.33). Generally, after combining studies through random effects model, the standardized mean score of height after treatment was estimated to be $0.11(95 \% \mathrm{CI}: 0.07-0.14)$ which is equivalent to $54.38 \%$ (mean score of their height came out to be than 54\% of participants) (Fig. 4).

Before treatment, percentile of children's height according to mean of SD (MSD) was obtained to be -1.64 (95\% CI: -2.01 to -1.28 ) that was equal to $5 \%$. In the same way, after treatment according to MSD, percentile of children's height came out to be $0.11(95 \%$ CI: $0.07-0.14)$ that was equal to $54.38 \%$. This shows that increase in the percentile of children's height is due to treatment with growth hormone.

Therefore, through combining the results of all studies, the mean score of participants' height before treatment was higher than $5 \%$ of participants; however, after treatment, $54 \%$ of participants grew taller, so in the absence of treatment, it is expected to remain at the same $5 \%$.

Differences in the mean score of adult height after treatment with growth hormone was reported to be more than 1.4 SD score (about $7.6 \mathrm{~cm}$ ).

In addition, heterogeneity of studies was, totally, $60.2 \%$ which is considered as moderate heterogeneity which is significant with a P-value of 0.000 .

\section{The effect of treatment duration on the final height increase}

Treatment duration has been classified into three groups. SMD among persons whose treatment duration was 4 years or less was reported to be 0.12 (95\% CI: $0.10-0.14)$, it was 0.06 (95\% CI: 0.05 - 0.07) in persons whose treatment duration was 4 - 6 years, and finally among those with a treatment duration of 6 years or more was 0.08 (95\% CI: $0.00-0.15)$. Generally, according to the combination of studies through random effect model, SMD for height was calculated to be 


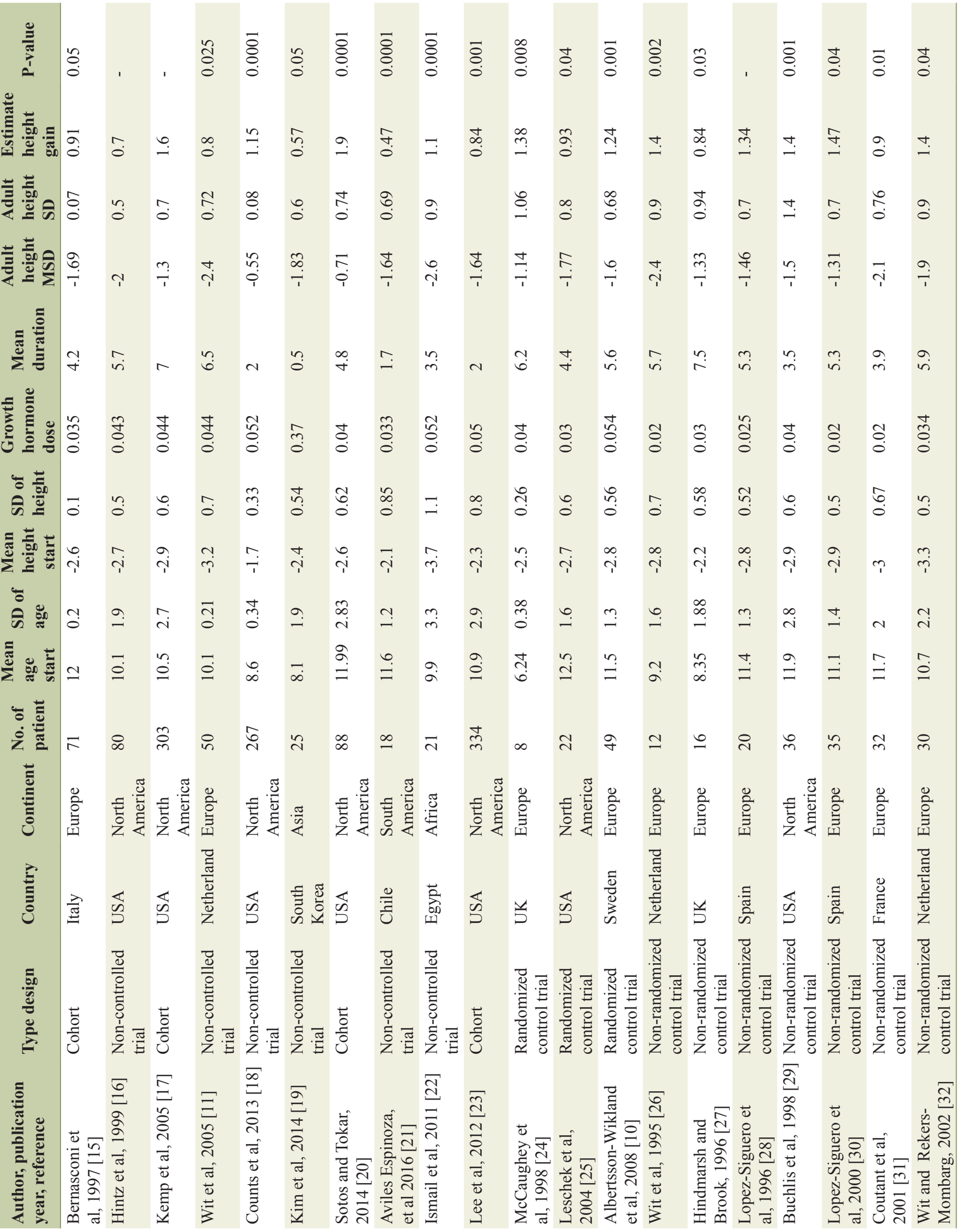




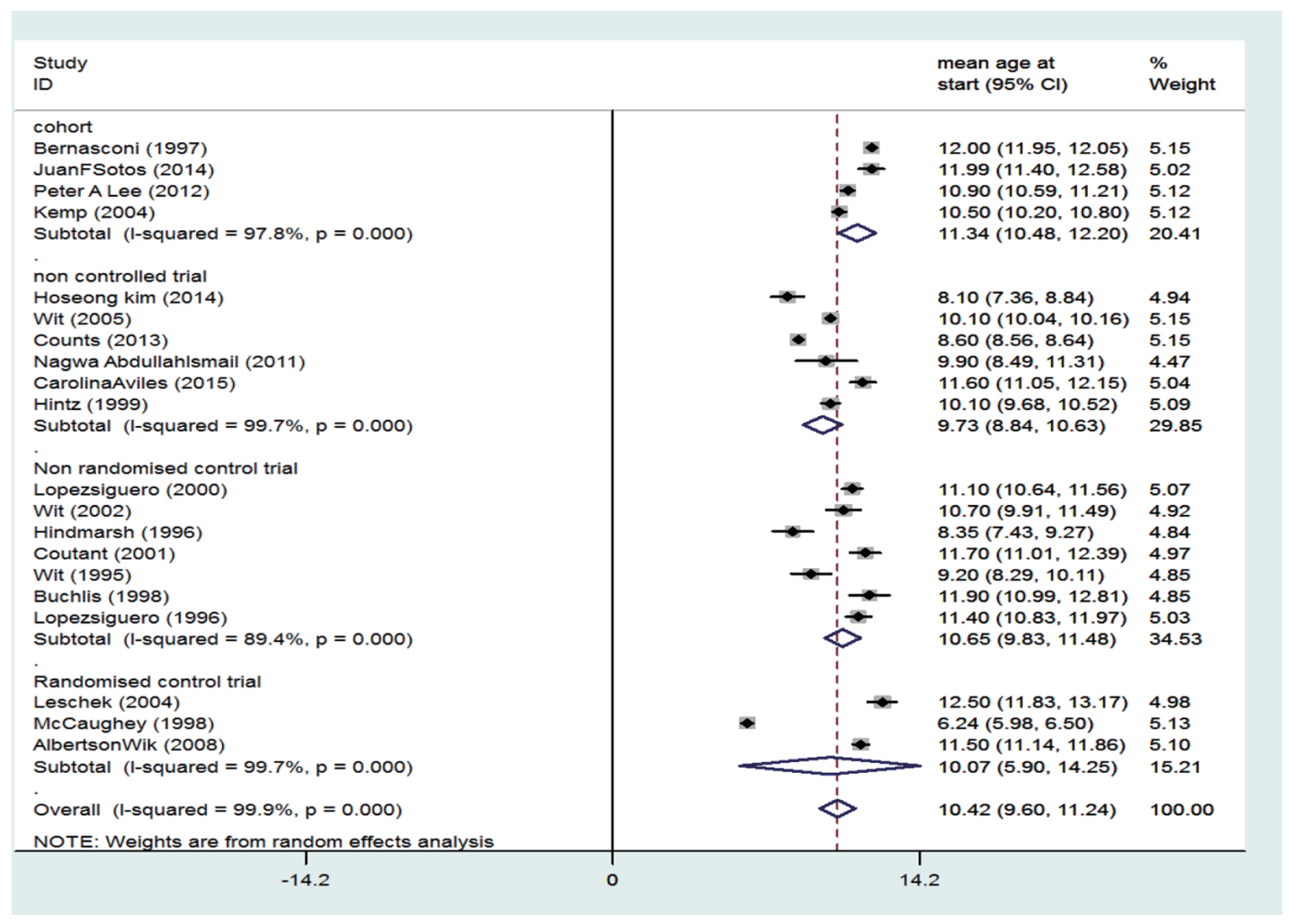

Figure 2. Mean score of participants' treatment start age.

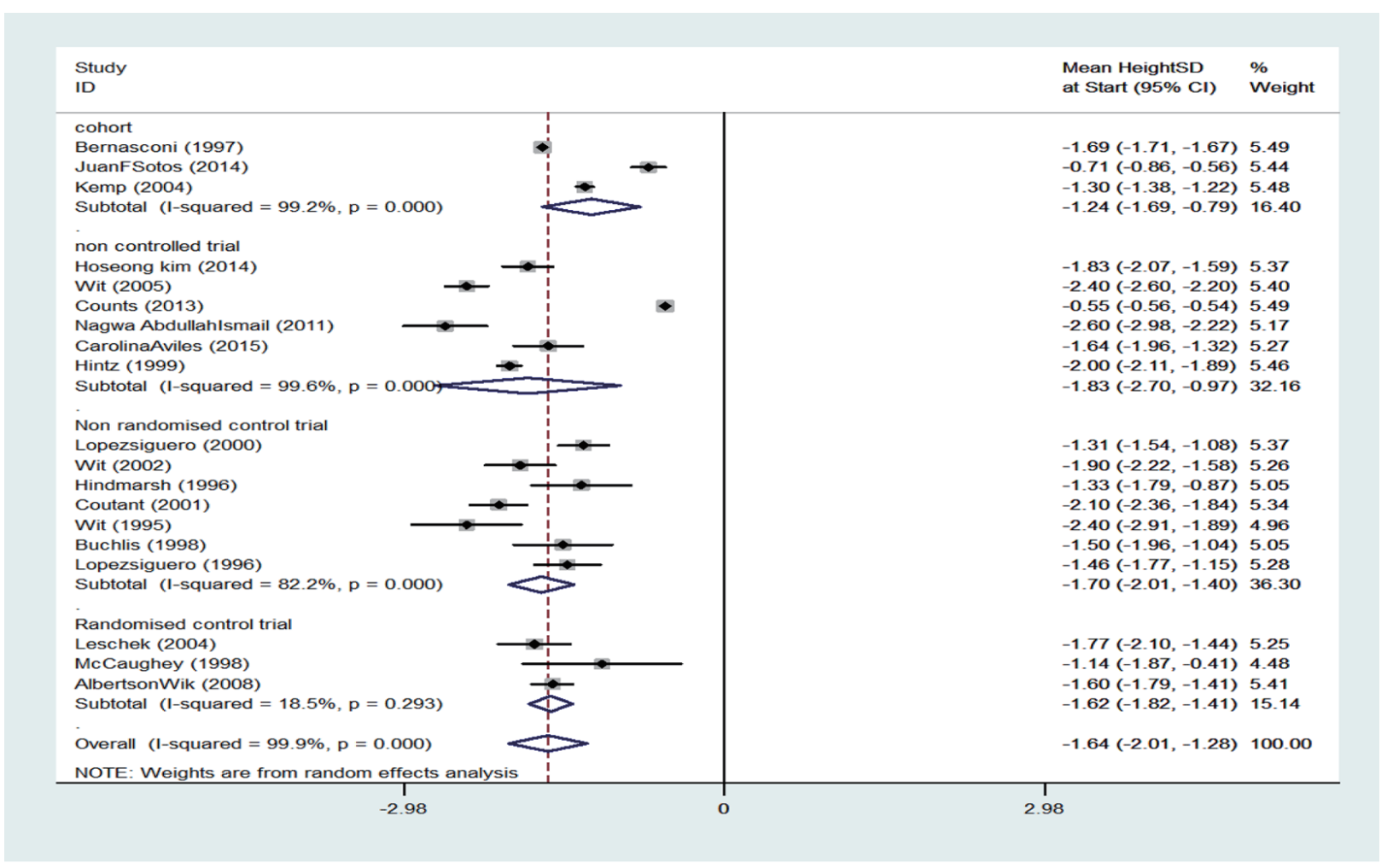

Figure 3. Mean score of height before treatment start. 


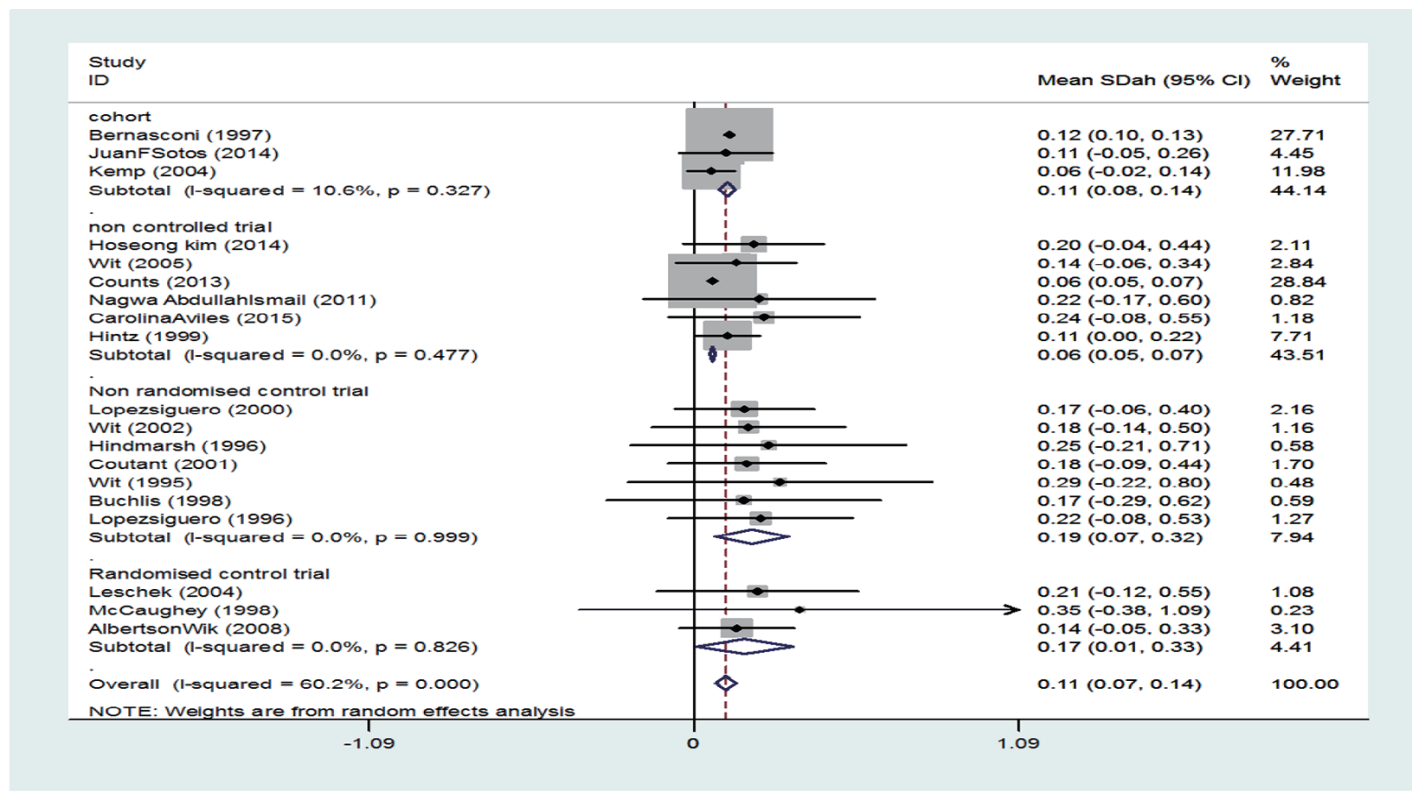

Figure 4. Mean score of height after treatment.

$0.11(95 \% \mathrm{CI}: 0.07-0.15)$ which is equivalent to $54.38 \%$ (Fig. 5).

\section{The effect of received dose on the final height}

Received doses are divided into two classes. SMD in persons receiving doses less than $0.04 \mathrm{mg} / \mathrm{kg} /$ day was 0.12 (95\% CI: $0.10-0.14$ ) and among person receiving doses more than 0.04 mg/kg/day was 0.06 (95\% CI: 0.05 - 0.07) (Fig. 6).

\section{Relationship between treatment duration and final height increase}

The longer the treatment duration, the more the mean score of height, but this increase is not statistically significant $(\mathrm{P}>$ 0.05) (Fig. 7).

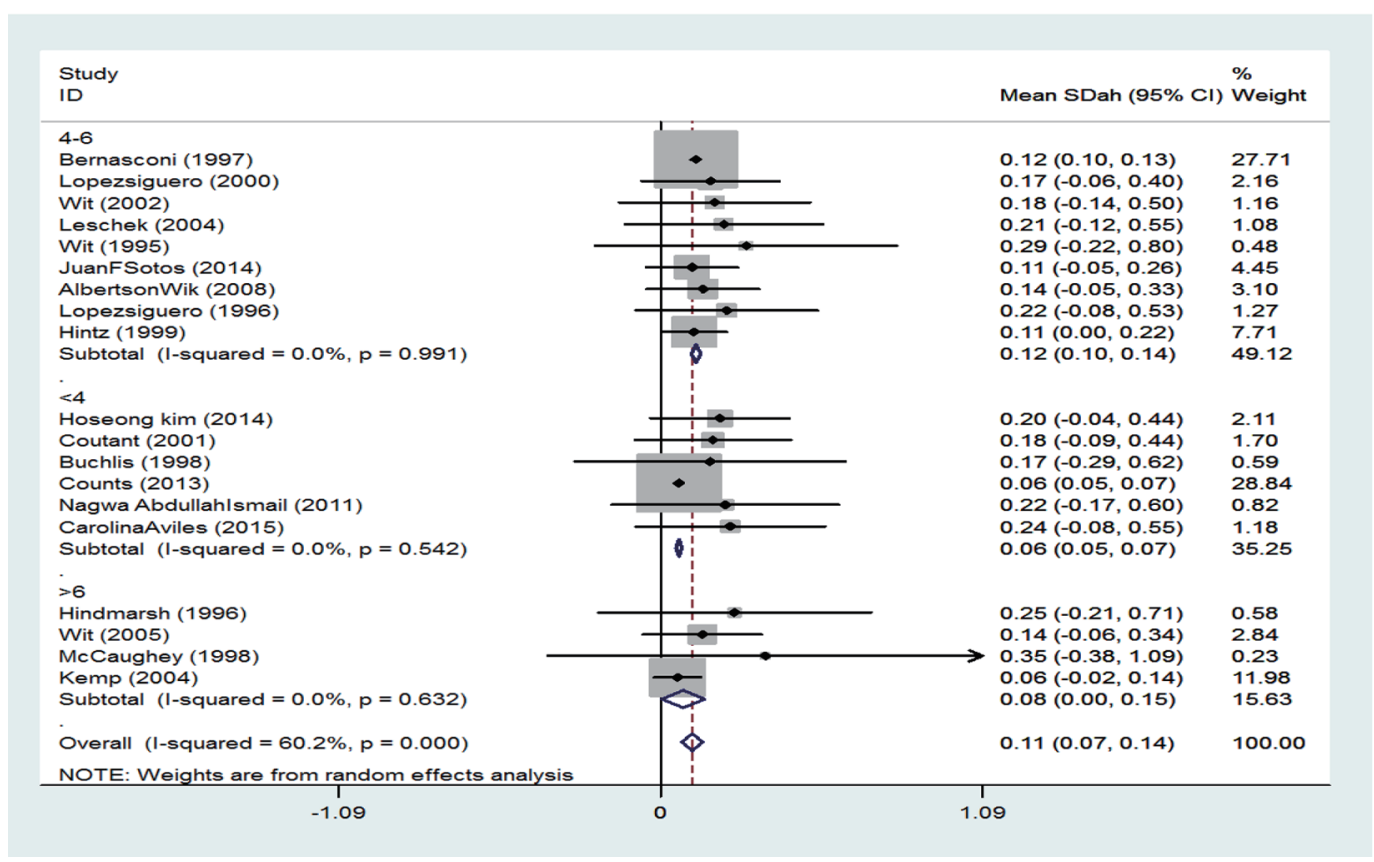

Figure 5. The effect of treatment duration on the final height. 
Study

ID

$<.04$

Bernasconi (1997)

Hoseong kim (2014)

Lopezsiguero (2000)

Wit (2002)

Leschek (2004)

Hindmarsh (1996)

Coutant (2001)

McCaughey (1998)

Wit (1995)

JuanFSotos (2014)

Buchlis (1998)

CarolinaAviles (2015)

Lopezsiguero (1996)

Subtotal (l-squared $=0.0 \%, p=0.992$ )

$>.04$

Wit (2005)

AlbertsonWik (2008)

Counts (2013)

Nagwa Abdullahlsmail (2011)

Kemp (2004)

Hintz (1999)

Subtotal (l-squared $=0.0 \%, p=0.736$ )

Overall (l-squared $=60.2 \%, p=0.000)$

NOTE: Weights are from random effects analysis

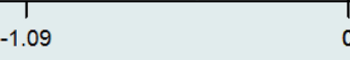

$\%$

Mean SDah $(95 \% \mathrm{Cl})$ Weight

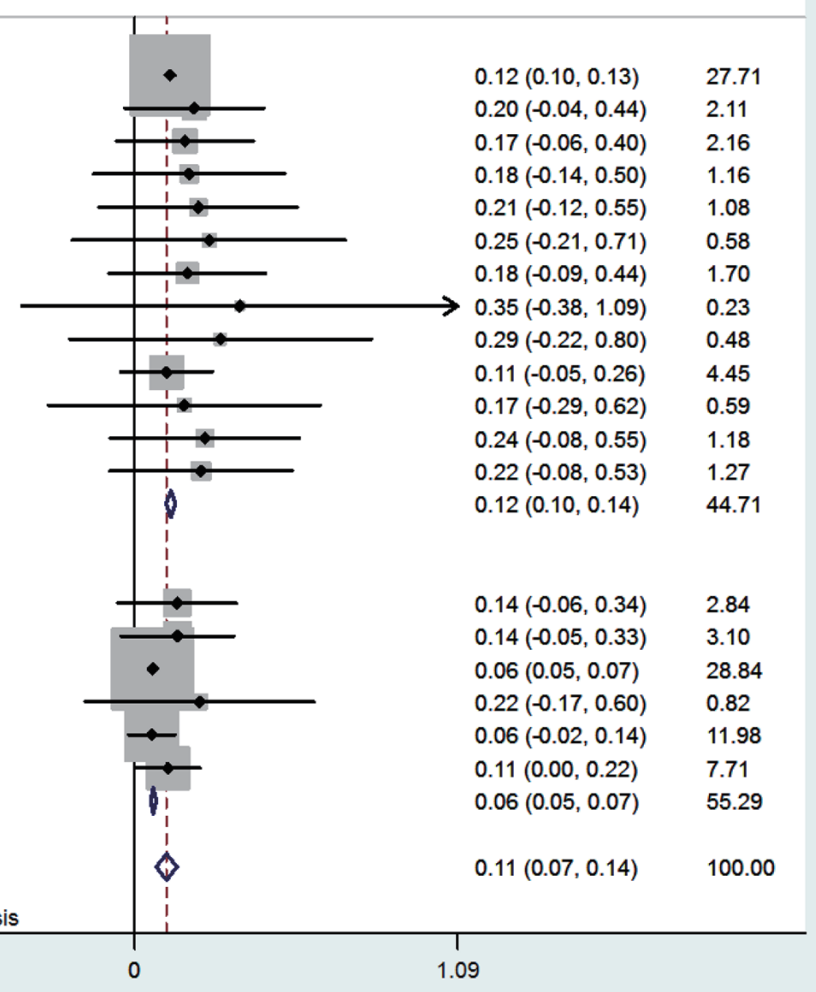

Figure 6. The effect of received dose on the final height increase.

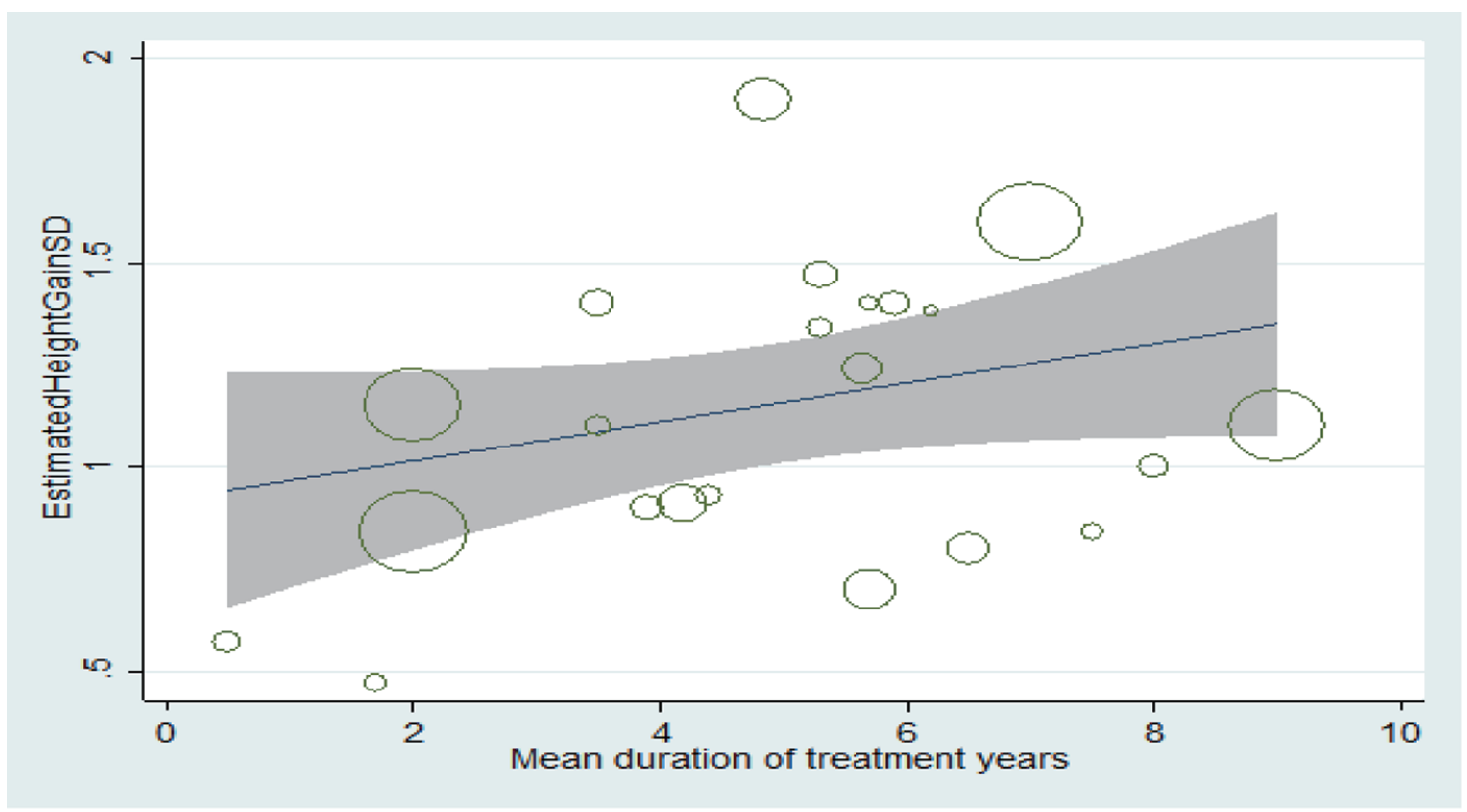

Figure 7. Relationship between treatment duration and final height increase. 


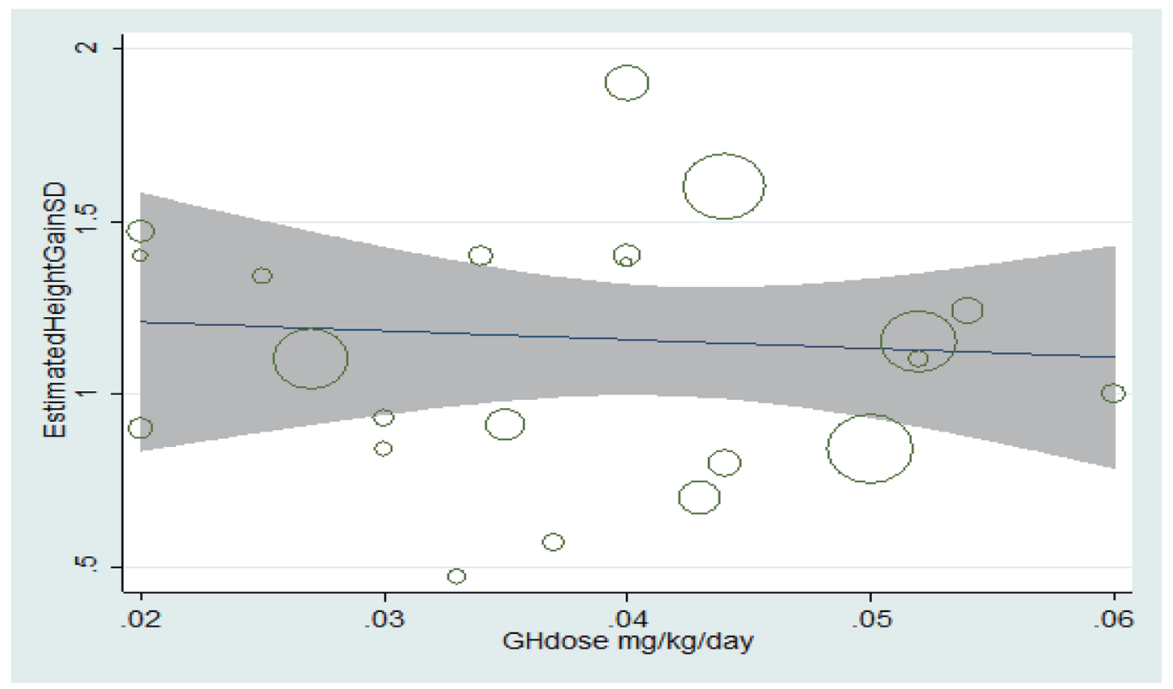

Figure 8. Relationship between the consumed dose and increase in final height.

\section{Relationship between the consumed dose and final height increase}

Treatment with growth hormone has had an incremental effect on the final height; however, the relationship between height increase and increasing the consumed dose was statistically insignificant $(\mathrm{P}>0.05)$ (Fig. 8).

\section{Begg's funnel plot}

This plot was used to check publication bias and showed that the effect of publication bias was not significant with a P-value more than 0.05 (Fig. 9).

\section{Discussion}

In this meta-analysis study, there were 20 clinical trial studies investigating the effect of growth hormone on the adult height of children with ISS. It was attempted to select only studies with high quality. Results of the current study indicated that before treatment, SMD for height was $-1.64(95 \%$ CI: -2.01 to -1.28$)$ which was equal to $5 \%$ and after treatment SMD for height increased to 0.11 (95\% CI: $0.07-0.14)$ which is equal to $54.38 \%$. The obtained mean difference for adult height after treatment with growth hormone was estimated to be approximately equal to SD score (about $6.7 \mathrm{~cm}$ ) while according to a meta-analysis conducted by Deodati et al [14], mean difference for adult height after treatment with

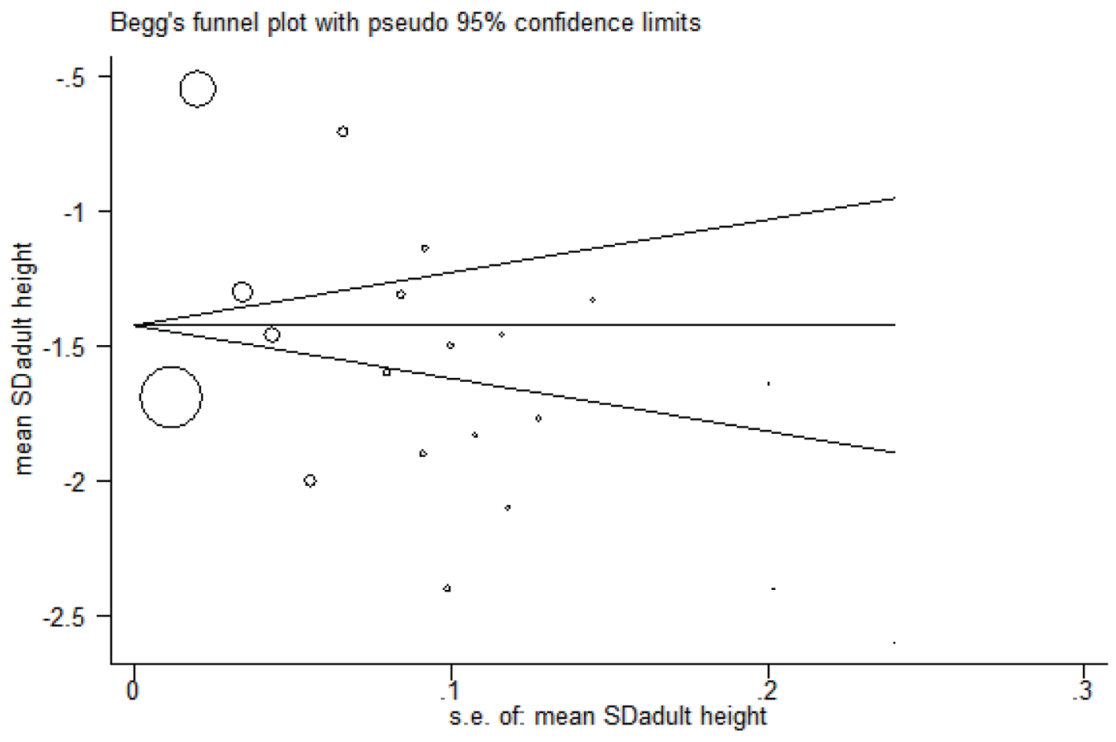

Figure 9. Begg's funnel plot. 
growth hormone was equal to SD score $(0.57-0.70$ (3.4 $4.2 \mathrm{~cm})$ ); therefore, the differences between the results of the current study and Deodati's study indicate that SMD for adult height has increased due to growth hormone as compared to before treatment.

\section{Strengths of the study}

Most of studies were clinical trial studies and results of these studies are more reliable. In the current study, analysis was carried out according to cohort and clinical trial classification of studies and SMD for height has been calculated for each group. Then, random effect model was utilized to combine the studies and overall results were also estimated. Just studies of high quality and weight were included in the meta-analysis. Throughout all process of meta-analysis heterogeneity was estimated.

\section{Weaknesses of the study}

The most important limitation of this study was the heterogeneity of the population understudy. Some studies were excluded because the reason of low height was not specified. Further, there were some studies that had a small sample size; in such studies, the existence of bias is more probable. It was impossible to accomplish searching process through combined use of keywords in external and internal data bases. Many studies were excluded due to insufficient epidemiologic information.

\section{Conclusion}

The present meta-analysis contained cohort, randomized controlled trials and non-randomized controlled trials studies of growth hormone therapy. Growth hormone can be influential in increasing the adult height of children with ISS up to the achievement of adult height in children with ISS.

\section{Acknowledgments}

The authors gratefully acknowledge the Research Council of Ilam University of Medical Sciences for the financial support.

\section{Conflicts of Interest}

There are no conflicts of interest.

\section{Funding Source}

Vice-chancellor of Ilam University of Medical Sciences supports the funding of this work.

\section{References}

1. Brook CGD. Clinical pediatric endocrinology. London: Black Well Science. 1995:136-193.

2. Kosarian M, Valayee N. A study Comparing Response to Growth hormone in two groups of children. Journal of Mazandaran University of Medical Sciences. 2001;11(30):1-7.

3. Abbassi V. Growth and normal puberty. Pediatrics. 1998;102(2 Pt 3):507-511.

4. UNICEF - Child Nutrition Report 2013w.

5. Wit JM. Definition and subcategorization of idiopathic short stature: between consensus and controversy. Horm Res Paediatr. 2011;76(Suppl 3):3-6.

6. Ranke MB. Towards a consensus on the definition of idiopathic short stature. Horm Res. 1996;45(Suppl 2):64-66.

7. Pedicelli S, Peschiaroli E, Violi E, Cianfarani S. Controversies in the definition and treatment of idiopathic short stature (ISS). J Clin Res Pediatr Endocrinol. 2009;1(3):105-115.

8. Cohen P, Rogol AD, Deal CL, Saenger P, Reiter EO, Ross JL, Chernausek SD, et al. Consensus statement on the diagnosis and treatment of children with idiopathic short stature: a summary of the Growth Hormone Research Society, the Lawson Wilkins Pediatric Endocrine Society, and the European Society for Paediatric Endocrinology Workshop. J Clin Endocrinol Metab. 2008;93(11):42104217.

9. Finkelstein BS, Imperiale TF, Speroff T, Marrero U, Radcliffe DJ, Cuttler L. Effect of growth hormone therapy on height in children with idiopathic short stature: a metaanalysis. Arch Pediatr Adolesc Med. 2002;156(3):230240.

10. Albertsson-Wikland K, Aronson AS, Gustafsson J, Hagenas L, Ivarsson SA, Jonsson B, Kristrom B, et al. Dosedependent effect of growth hormone on final height in children with short stature without growth hormone deficiency. J Clin Endocrinol Metab. 2008;93(11):43424350.

11. Wit JM, Rekers-Mombarg LT, Cutler GB, Crowe B, Beck TJ, Roberts K, Gill A, et al. Growth hormone (GH) treatment to final height in children with idiopathic short stature: evidence for a dose effect. J Pediatr. 2005;146(1):4553.

12. Ranke MB, Lindberg A, Price DA, Darendeliler F, Albertsson-Wikland K, Wilton P, Reiter EO. Age at growth hormone therapy start and first-year responsiveness to growth hormone are major determinants of height outcome in idiopathic short stature. Horm Res. 2007;68(2):53-62.

13. Moher D, Liberati A, Tetzlaff J, Altman DG. Preferred reporting items for systematic reviews and metaanalyses: the PRISMA statement. Int J Surg. 2010;8(5):336-341.

14. Deodati A, Cianfarani S. Impact of growth hormone therapy on adult height of children with idiopathic short stature: systematic review. BMJ. 2011;342:c7157.

15. Bernasconi S, Street ME, Volta C, Mazzardo G. Final height in non-growth hormone deficient children treat- 
ed with growth hormone. The Italian Multicentre Study Group. Clin Endocrinol (Oxf). 1997;47(3):261-266; discussion 267.

16. Hintz RL, Attie KM, Baptista J, Roche A. Effect of growth hormone treatment on adult height of children with idiopathic short stature. Genentech Collaborative Group. N Engl J Med. 1999;340(7):502-507.

17. Kemp SF, Kuntze J, Attie KM, Maneatis T, Butler S, Frane J, Lippe B. Efficacy and safety results of long-term growth hormone treatment of idiopathic short stature. J Clin Endocrinol Metab. 2005;90(9):5247-5253.

18. Counts DR, Silverman LA, Geffner ME, Rajicic N, Hey-Hadavi J, Thornton PS, Wajnrajch MP. A four-year, open-label, multi-center, randomized, two-arm study of Genotropin(R) in patients with idiopathic short stature: comparison of an individualized, target-driven treatment regimen to standard dosing of Genotropin(R) - analysis of two-year data. Horm Res Paediatr. 2013;80(4):242-251.

19. Kim HS, Yang SW, Yoo HW, Suh BK, Ko CW, Chung WY, Lee KH, et al. Efficacy of short-term growth hormone treatment in prepubertal children with idiopathic short stature. Yonsei Med J. 2014;55(1):53-60.

20. Sotos JF, Tokar NJ. Growth hormone significantly increases the adult height of children with idiopathic short stature: comparison of subgroups and benefit. Int J Pediatr Endocrinol. 2014;2014(1):15.

21. Aviles Espinoza C, Bermudez Melero C, Martinez Aguayo A, Garcia Bruce H. [Adult height of children with idiopathic short stature treated with growth hormone therapy]. Rev Chil Pediatr. 2016;87(1):37-42.

22. Ismail NA, Metwaly NS, El-Moguy FA, Hafez $\mathrm{MH}$, El Dayem SM, Farid TM. Growth response of Egyptian children with idiopathic short stature during four years of growth hormone therapy. Indian J Hum Genet. 2011;17(3):218-225.

23. Lee PA, Savendahl L, Oliver I, Tauber M, Blankenstein O, Ross J, Snajderova M, et al. Comparison of response to 2-years' growth hormone treatment in children with isolated growth hormone deficiency, born small for gestational age, idiopathic short stature, or multiple pituitary hormone deficiency: combined results from two large observational studies. Int $\mathrm{J}$ Pediatr Endocrinol.
2012;2012(1):22.

24. McCaughey ES, Mulligan J, Voss LD, Betts PR. Randomized trial of growth hormone in short normal girls. Lancet. 1998;351:940-944.

25. Leschek EW, Rose SR, Yanovski JA, Troendle JF, Quigley CA, Chipman JJ, Crowe BJ, et al. Effect of growth hormone treatment on adult height in peripubertal children with idiopathic short stature: a randomized, doubleblind, placebo-controlled trial. J Clin Endocrinol Metab. 2004;89(7):3140-3148.

26. Wit JM, Boersma B, de Muinck Keizer-Schrama SM, Nienhuis HE, Oostdijk W, Otten BJ, Delemarre-Van de Waal HA, et al. Long-term results of growth hormone therapy in children with short stature, subnormal growth rate and normal growth hormone response to secretagogues. Dutch Growth Hormone Working Group. Clin Endocrinol (Oxf). 1995;42(4):365-372.

27. Hindmarsh PC, Brook CG. Final height of short normal children treated with growth hormone. Lancet. 1996;348(9019):13-16.

28. Lopez-Siguero JP, Martinez-Aedo MJ, Moreno-Molina JA. Final height after growth hormone therapy in children with idiopathic short stature and a subnormal growth rate. Acta Pediatr. 1996;85:113-147.

29. Buchlis JG, Irizarry L, Crotzer BC, Shine BJ, Allen L, MacGillivray MH. Comparison of final heights of growth hormone-treated vs. untreated children with idiopathic growth failure. J Clin Endocrinol Metab. 1998;83(4):1075-1079.

30. Lopez-Siguero JP, Garcia-Garcia E, Carralero I, Martinez-Aedo MJ. Adult height in children with idiopathic short stature treated with growth hormone. J Pediatr Endocrinol Metab. 2000;13(9):1595-1602.

31. Coutant R, Rouleau S, Despert F, Magontier N, Loisel D, Limal JM. Growth and adult height in GH-treated children with nonacquired GH deficiency and idiopathic short stature: the influence of pituitary magnetic resonance imaging findings. J Clin Endocrinol Metab. 2001;86(10):4649-4654.

32. Wit JM, Rekers-Mombarg LT. Final height gain by GH therapy in children with idiopathic short stature is dose dependent. J Clin Endocrinol Metab. 2002;87(2):604-611. 